\title{
Burned-Out Bladder Tumor
}

\author{
Achraf Chatar, ${ }^{\otimes 1}$ Jihad El Anzaoui, ${ }^{2}$ Ali Akjay, ${ }^{2}$ Ahmed Ameziane, ${ }^{1}$ Abdenasser Lakrabti, ${ }^{2}$ \\ Abdelghani Ammani²
}

${ }^{1}$ CHU Hassan II, Fes, Fès-Meknès, Morocco ${ }^{2}$ Military hospital Moulay Ismail Meknes, Morocco

We present the case of a 64-year-old man with intermittent hematuria dating back more than 6 months. A bladder mass was found on ultrasound, and endoscopic evaluation revealed a necrotic whitish intraluminal bladder mass (Figure 1). The patient underwent complete transurethral resection of this bladder mass. The anatomopathological examination found a necrotic inflammatory lesion, with ghosts of neoplastic cells but no viable neoplastic cells throughout (Figure 2).

\section{FIGURE 1.}

Endoscopic aspect of bladder tumor

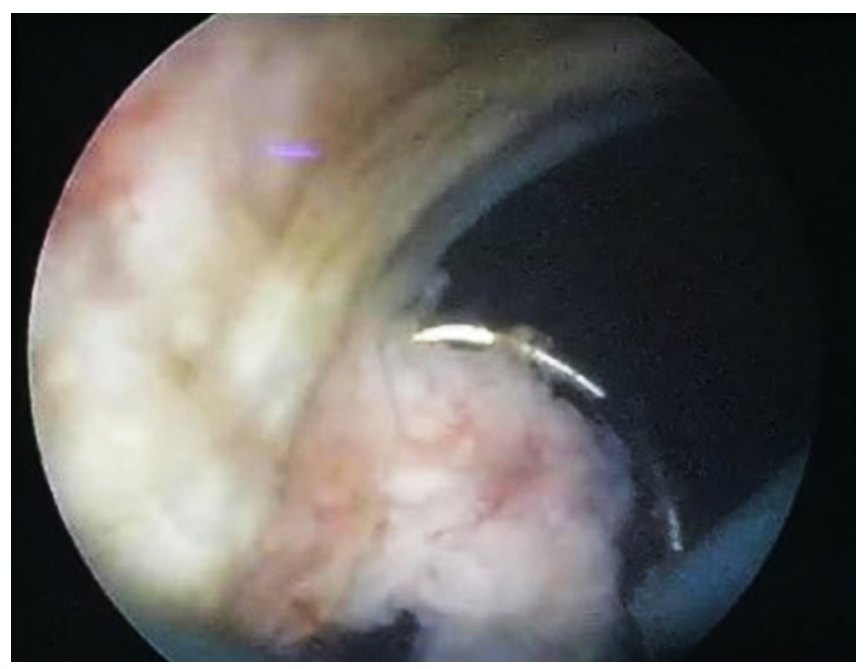

\section{Reference}

1. Cheng $L$, Lyu B, Roth $L M$. Perspectives on testicular germ cell neoplasms. Hum Pathol.2017;59:10-25. doi: 10.1016/j.humpath.2016.08.002.
FIGURE 2.

Anatomopathological aspect of the tumor

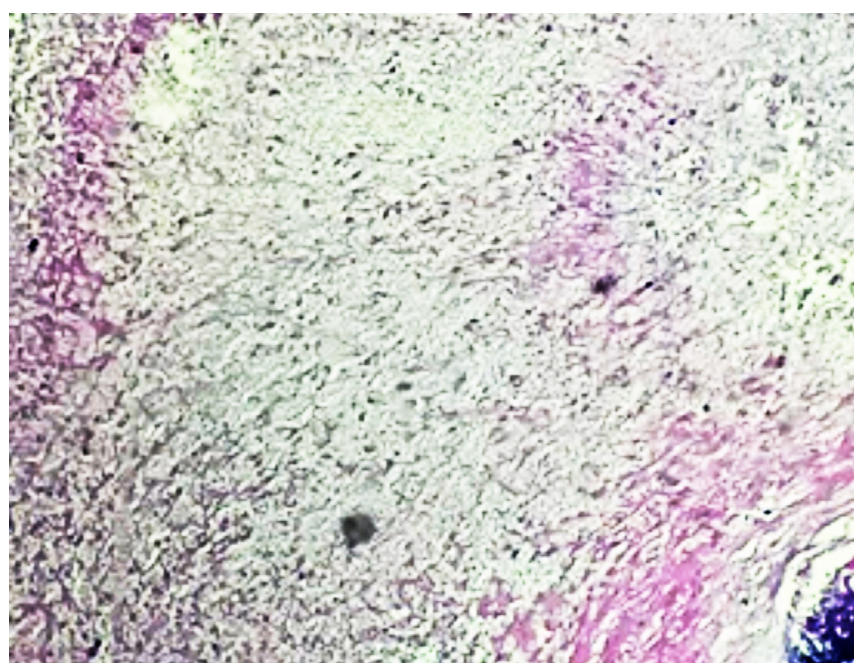

Cross-sectional imaging revealed no additional disease. The patient was followed up with cystoscopy and computed tomography, and no recurrence was noted after 6 months.

Burned-out tumor, in which the initial tumor has completely or partially necrosed, is reported rarely in testicular cancer[1], but, to the best of our knowledge, has never previously been reported in bladder cancer.

\section{Key Words}

Burned-out, tumor, bladder cancer
Competing Interests

None declared.

Patient Consent: Obtained.

\section{Article Information}

Received on February 17, 2021

Accepted on March 11, 2021

Soc Int Urol J.2021;2(3):188

DOI: 10.48083/0GJU1775 